\title{
Aspirations, Habit Formation, and Bequest Motive*
}

\author{
Jaime Alonso-Carrera \\ Departamento de Economia Aplicada and RGEA \\ Universidade de Vigo \\ Jordi Caballé \\ Unitat de Fonaments de l'Anàlisi Economica and CODE \\ Universitat Autònoma de Barcelona \\ Xavier Raurich \\ Departament d'Economia, Universitat de Girona; \\ and CREB, Universitat de Barcelona
}

July 21,2004

\begin{abstract}
We analyze how the presence of endogenous preferences affects the altruistic bequest motive from parents to children. We will show that the existence of habits raises the threshold value of the intergenerational discount factor above which altruistic bequests are positive, while aspiration formation could push this value down. Therefore, the dynamic inefficiency of the economy with no altruism is not sufficient to prevent the bequest motive from being operative under aspiration formation. We also discuss the implications of public debt when the bequest motive is inoperative and preferences exhibit habit and aspiration formation.
\end{abstract}

JEL classification codes: E21, E13, E62.

Keywords: Aspirations, Habits, Bequests.

${ }^{*}$ Financial support from the Spanish Ministry of Science and Technology through grants SEC2003-00306 and BEC2002-01995; the Generalitat of Catalonia through the Barcelona Economics program (CREA) and grant SGR2001-00162; and the Xunta of Galicia through grant PGIDIT03PXIC30001PN are gratefully acknowledged.

Correspondence address: Jordi Caballé. Universitat Autònoma de Barcelona. Departament d'Economia i d'Història Econòmica. Edifici B. 08193 Bellaterra (Barcelona). Spain.

Phone: (34)-935.812.367. Fax: (34)-935.812.012. E-mail: Jordi.Caballe@uab.es 


\section{Introduction}

A recent strand of the economics literature has analyzed the theoretical and empirical implications of the existence of endogenous preferences, that is, preferences that depend on time, personal experience or social conditions. Among the different kinds of endogenous preferences we can mention those displaying habits or aspirations. By habits we mean that the utility associated with a given amount of current consumption depends on the past experience of consumption of the individual under consideration. By aspirations we mean instead that the utility of individuals depends on the consumption experience of their antecessors. In both cases, past consumption is used as a reference with respect which current own consumption is compared to.

Among the papers introducing habits in infinite horizon models we can mention those of Abel (1990, 1999); Lettau and Uhlig (2000); Ljungqvist and Uhlig (2000); Fuhrer (2000); Carroll et al. (1997, 2000); Shieh et al. (2000) and Alonso-Carrera et al. (2004a, 2004b). Some other authors have analyzed the implications of endogenous preferences on saving, capital accumulation and dynamic stability in overlapping generations (OLG) models. Lahiri and Puhakka (1998) study the effect of habits intensity on saving in a pure exchange economy. Wedner (2002) extends the previous work to a economy with production and capital accumulation. De la Croix (1996) and De la Croix and Michel (1999, 2001) analyze several stability issues in an OLG economy with aspirations and inherited preferences. Finally, Abel (2003) characterizes the optimal fiscal policy in an OLG economy when consumption externalities are present.

In the present paper we study the implications of the interaction of altruism with habit and aspiration formation. To this end we should point out that habits and aspirations are intertemporal phenomena displaying different features. Habit formation has an intragenerational nature, whereas aspiration formation has an intergenerational one. The interaction of this two phenomena with another featuring intergenerational links, like altruism, can affect the dynamic behavior of the economy. In particular, while aspirations display intergenerational effects regardless of whether individuals are altruistic or not, habit formation exhibits intergenerational effects only through the potential altruistic linkages among individuals belonging to different generations. Therefore, the main target of our work is to analyze whether the presence of habit and aspiration formation affects the altruistic bequest motive from parents to children.

We aim at contributing to the literature on the economic implications of intergenerational altruism by analyzing whether the result obtained by Weil (1987) on the Ricardian equivalence proposition (see Barro, 1974) holds under endogenous preferences. ${ }^{1}$ Weil showed that altruism is not strong enough to generate positive bequests in a dynamically inefficient economy, as defined in Cass (1972). We will show that endogenous preferences affects the potential of altruism as a source of intentional bequests. In particular, the existence of habits raises the threshold value of the intergenerational discount factor above which altruistic bequests are positive, while aspiration formation could push this value down. Therefore, and in contrast

\footnotetext{
${ }^{1}$ See, among many others, the related papers papers by Abel (1987), Caballé (1995, 1998), and Dynan et al. (2002).
} 
with Weil's analysis, the dynamic inefficiency of the economy with no altruism is not sufficient to prevent the bequest motive from being operative when individuals want to reach the standard of living of their parents. Finally, as a by-product of our analysis, we will characterize the long run effects of both habits and aspirations on the capital stock and on the amount of bequests when the bequest motive is operative. On the one hand, we show that an increase in the habits intensity increases the amount of old consumption since stronger habits reduce the overall utility accruing from early consumption. This can be achieved by means of either increasing savings or reducing the amount of bequests left to the descendants. In particular, we show that if the bequest motive is operative the amount of saving remains constant and a reduction in the amount of bequests takes place, whereas if the bequest motive is inoperative the amount of saving increases. On the other hand, an increase in aspirations intensity makes individuals raise the amounts of both saving and bequests in order to outweigh the negative effect of stronger aspirations on their descendants utility.

Other papers conducting analyses related to ours are those of De la Croix and Michel (2001) and Jellal and Wolff (2002). The former paper analyzes the differences concerning dynamic behavior between an economy with aspiration formation and operative bequest motive and an economy with no bequests. Moreover, the authors present a numerical example aimed at illustrating how aspirations affect the operativeness of the bequest motive. Our aim is to generalize their result and extend it to the case where habit formation is also present. In fact, we will show that this generalization is far from trivial and that the case analyzed by De la Croix and Michel is very particular. Furthermore, the introduction of habits seems natural since it would be otherwise difficult to argue that individuals take into account the past consumption level achieved by their parents but not their own past consumption experience. However, we will see that aspirations and habits have opposite effects on the operativeness of the bequest motive. Therefore, the overall effect of the presence of endogenous preferences on the potential existence of positive bequests is thus ambiguous. The paper of Jellal and Wolff (2002) analyzes how the aspiration formation affects the amount of bequests left by parents to their children. In contrast with our work, these authors consider a finite horizon economy so that only two generations exist in their economy.

The inoperativeness of the bequest motive implies that the neutrality of public debt, resulting from the Ricardian equivalence proposition, does not longer hold. We show that the crowding out effect associated with government deficits also arises when habits and aspirations are present.

The paper is organized as follows. Section 2 presents the general model with both habits and aspirations. Section 3 analyzes the potential inoperativeness of the bequest motive in our general setup. In Sections 4 and 5 we conduct the comparative statics on the threshold level of altruism below (above) which bequests are zero (positive) of changes in the intensity of habits and aspirations, respectively. Section 6 analyzes the effects of public debt when the bequest motive is inoperative under habit and aspiration formation. Section 7 concludes the paper. 


\section{The Model}

Let us consider a OLG model where a continuum of identical individuals live for three periods and a new generation is born in each period. Each individual has offspring in the second period of his life and the number of children per parent is $n \geq 1$. Agents take economic decisions during the last two periods of their lives only. In every period, the youngest individuals neither work nor consume. However, following De la Croix (1996) the members of the youngest generation in period $t$ inherit some level of aspirations $a_{t+1}$ in period $t+1$. These aspirations are based on the standard of living achieved by their parents. More precisely, we assume that

$$
a_{t+1}=c_{t}^{1},
$$

where $c_{t}^{1}$ is the amount of consumption of their parents when they (the parents) were adults (second period of life). Individuals are assumed to be altruistic towards their children and they can leave bequests. Let $b_{t}$ be the amount of bequests that an old individual (born in period $t-2$ ) leaves to each of their direct descendants (who were born in period $t-1$ ) in period $t$.

There is a single commodity, which can be devoted to either consumption or investment. Each agent supplies inelastically one unit of labor in the second period of his life and is retired in the last period of his life. Let us index each generation by the period in which its members work. Each adult individual distributes his labor income and his inheritance between consumption and saving. The budget constraint faced by a worker (adult) in period $t$ is

$$
w_{t}+b_{t}=c_{t}^{1}+s_{t},
$$

where $w_{t}$ is the labor income and $s_{t}$ is the amount saved. When individuals are old, they receive a return on the amount of their saving, which is distributed between consumption and bequests for their children. Therefore, the budget constraint of an old individual belonging to the generation $t$ will be

$$
R_{t+1} s_{t}=c_{t+1}^{2}+n b_{t+1},
$$

where $R_{t+1}$ is the gross rate of return on saving and $c_{t+1}^{2}$ is the amount of consumption of an old individual in period $t+1$. Let us thus note that the superindex 1 on consumption refers to an adult individual (worker), while the superindex 2 refers to an old individual.

We also impose the constraint that parents cannot force their children to give them gifts when they (the parents) are old,

$$
b_{t} \geq 0
$$

The preferences of an individual belonging to the generation $t$ is given by the following utility function,

$$
V_{t}=U\left(\hat{c}_{t}^{1}, \hat{c}_{t+1}^{2}\right)+\beta V_{t+1},
$$


where $V_{t+1}$ represents the indirect utility of each of his descendants and the parameter $\beta \in[0,1)$ is the altruism factor. ${ }^{2}$ For tractability, let us assume that the function $U(\cdot, \cdot)$ is twice continuously differentiable and additive in its two argument as in Abel (1986) or Laitner (1988). Therefore, we use the following specification:

$$
U\left(\hat{c}_{t}^{1}, \hat{c}_{t+1}^{2}\right)=u\left(\hat{c}_{t}^{1}\right)+\rho u\left(\hat{c}_{t+1}^{2}\right),
$$

where $\rho>0$ is the temporal discount factor. We assume that $u^{\prime}>0, u^{\prime \prime}<0$, $\lim _{\hat{c} \rightarrow 0} u^{\prime}(c)=\infty$ and $\lim _{\hat{c} \rightarrow \infty} u^{\prime}(c)=0$.

The variables $\hat{c}_{t}^{1}$ and $\hat{c}_{t+1}^{2}$ represent the effective consumption in adult and old ages, respectively, of a representative individual belonging to generation $t$. We will assume that in each period individuals derive utility from the comparison of their consumption with some consumption reference. These references will be endogenous. On the one hand, the consumption reference during adulthood will be given by the aspirations $a_{t}$ inherited from their parents. Taking into account (2.1), we posit the following additive specification for the effective consumption of an adult individual in period $t$ :

$$
\hat{c}_{t}^{1}=c_{t}^{1}-\gamma a_{t}=c_{t}^{1}-\gamma c_{t-1}^{1} .
$$

This additive formulation for effective consumption allows to preserve the concavity of the objective function with respect to the consumption vector. On the other hand, the consumption reference of an old individual is determined by the consumption level he has reached in the previous period (habits). Hence, the effective consumption of an old individual in period $t+1$ is given by the additive function

$$
\hat{c}_{t+1}^{2}=c_{t+1}^{2}-\delta c_{t}^{1} .
$$

In the previous formulae for the effective consumption levels we assume that $\gamma$ and $\delta$ belong to the closed interval $[0,1]$. We make $\gamma \geq 0$ and $\delta \geq 0$ in order to be consistent with the notion of aspirations and habits, respectively. Moreover, to ensure that the utility function $U(\cdot, \cdot)$ is well defined we must impose that $\gamma \leq 1$ and $\delta \leq 1$ since the arguments of the utility function would take negative values at the steady state otherwise.

Let us assume that the good of this economy is produced by means of a neoclassical production function $F\left(K_{t}, L_{t}\right)$, where $K_{t}$ is the capital stock and $L_{t}$ is the amount of labor used in period $t$. The capital stock fully depreciate after one period. The production function per capita is $f\left(k_{t}\right)$, where $k_{t}$ is the capital stock per capita. As firms behave competitively, the rental prices of the two inputs equal their marginal productivities,

$$
\begin{gathered}
R_{t}=f^{\prime}\left(k_{t}\right) \equiv R\left(k_{t}\right), \\
w_{t}=f\left(k_{t}\right)-f^{\prime}\left(k_{t}\right) k_{t} \equiv w\left(k_{t}\right) .
\end{gathered}
$$

In equilibrium the capital stock installed in period $t+1$ is equal to the aggregate saving in period $t$ and, thus, we have

$$
n k_{t+1}=s_{t} .
$$

\footnotetext{
${ }^{2}$ We are implicitly assuming that each parent cares equally abouth the felicity of their $n$ children. Thus, the intercohort utility discount $\beta$ coud be rewriten as $\beta=n \rho \beta^{\prime}$, where $\rho$ would be the temporal discount factor and $\beta^{\prime}$ is the pure interpersonal (from parents to children) discount factor.
} 
The maximization of (2.5) with respect to $\left\{c_{t}^{1}, c_{t+1}^{2}, b_{t+1}\right\}$ subject to (2.2), (2.3), (2.4), (2.7) and (2.8), is equivalent to solving the following dynamic programming problem:

$$
\begin{aligned}
V_{t}\left(b_{t}, s_{t-1}\right) & =\max _{\left\{s_{t}, b_{t+1}\right\}}\left\{u(\underbrace{w_{t}+b_{t}-s_{t}-\gamma\left(w_{t-1}+b_{t-1}-s_{t-1}\right)}_{\hat{c}_{t}^{1}})\right. \\
& \left.\left.+\rho u(\underbrace{R_{t+1} s_{t}-n b_{t+1}-\delta\left(w_{t}+b_{t}-s_{t}\right)}_{\hat{c}_{t+1}^{2}})+\beta V_{t+1}\left(b_{t+1}, s_{t}\right)\right\}\right\},
\end{aligned}
$$

with $b_{t+1} \geq 0$, for $w_{t}$ and $R_{t+1}$ given for all $t$. The original state variables for each individual are the inheritance received and the acquired aspirations. Since aspirations coincide with the consumption of parents during adulthood and this consumption can be written as a function of parents' saving (see (2.2)), the state variables for the individuals of generation $t$ turn out to be the amount of bequests $b_{t}$ and the saving $s_{t-1}$ of their parents.

Using the envelope theorem we obtain,

$$
\begin{gathered}
\frac{\partial V_{t+1}}{\partial b_{t+1}}=u^{\prime}\left(\hat{c}_{t+1}^{1}\right)-\rho \delta u^{\prime}\left(\hat{c}_{t+2}^{2}\right), \\
\frac{\partial V_{t+1}}{\partial s_{t}}=\gamma u^{\prime}\left(\hat{c}_{t+1}^{1}\right) .
\end{gathered}
$$

Using (2.13) and (2.14), the first order conditions of problem (2.12) corresponding to the derivatives with respect to $s_{t}$ and $b_{t+1}$ are

$$
u^{\prime}\left(c_{t}^{1}-\gamma c_{t-1}^{1}\right)=\rho\left[R_{t+1}+\delta\right] u^{\prime}\left(c_{t+1}^{2}-\delta c_{t}^{1}\right)+\beta \gamma u^{\prime}\left(c_{t+1}^{1}-\gamma c_{t}^{1}\right),
$$

and

$$
n \rho u^{\prime}\left(c_{t+1}^{2}-\delta c_{t}^{1}\right) \geq \beta\left[u^{\prime}\left(c_{t+1}^{1}-\gamma c_{t}^{1}\right)-\delta \rho u^{\prime}\left(c_{t+2}^{2}-\delta c_{t+1}^{1}\right)\right],
$$

where the last condition holds with equality if $b_{t+1}>0$. Equation (2.15) gives us the optimal allocation of consumption along the lifetime of an individual. Note that this first order equation reflects the introduction of habits and aspirations since individuals are aware of the effect of their adult consumption on both their children utility and their own utility when old. Equation (2.16) characterizes the optimal level of bequests. This equation tells us that, when the bequest motive is operative $\left(b_{t+1}>0\right)$, the utility loss of parents arising from a larger amount of bequests must be equal to the discounted utility gain of their direct descendants. On the one hand, the left hand side of this equation gives us the utility loss experienced by an individual who decreases his old consumption in order to increase marginally the bequests left to their children. On the other hand, the right hand side of (2.16) gives us the discounted utility gain obtained by the descendants due to a marginal increase in the amount of inheritances. Note that the utility gain is determined by two effects. First, bequests allow its recipient to increase his adult consumption. Second, bequests reduce the utility of the recipient when old because of habit formation. 
The competitive equilibrium of this economy is thus given by the system of difference equations composed of (2.15) and (2.16), together with (2.2), (2.3), (2.4), (2.9), (2.10) and (2.11). Note that, in contrast with the standard model with exogenous preferences, the competitive equilibrium depends on the altruism factor $\beta$ even if the bequest motive is not operative $\left(b_{t}=0\right)$. More precisely, observe that when $\gamma>0$, the altruism factor $\beta$ appears explicitly in the first order condition (2.15). Therefore, the capital stock of an economy with aspiration formation and zero bequests, will depend on the altruism factor.

We are going to restrict our attention to stationary equilibria where all the endogenous variables remain constant. We will suppress the time subindex when we refer to the steady state value of a variable. Therefore, the first order conditions (2.15) and (2.16) evaluated at the steady state become

$$
[1-\beta \gamma] u^{\prime}\left(c^{1}-\gamma c^{1}\right)=\rho[R+\delta] u^{\prime}\left(c^{2}-\delta c^{1}\right),
$$

and

$$
\rho[n+\beta \delta] u^{\prime}\left(c^{2}-\delta c^{1}\right) \geq \beta u^{\prime}\left(c^{1}-\gamma c^{1}\right),
$$

where the last condition holds with equality whenever $b>0$.

From the budget constraints (2.2) and (2.3), the competitive rental prices (2.9) and (2.10), and the equilibrium condition (2.11), we obtain the following equations along the steady state:

$$
c^{1} \equiv c^{1}(k, b)=w(k)+b-n k
$$

and

$$
c^{2} \equiv c^{2}(k, b)=n k R(k)-n b .
$$

Using these steady state consumption levels and noticing that the aspirations level is equal to the adult consumption of the parent of the individual under consideration, (2.17) can be rewritten as

$$
\begin{aligned}
& h(k, b) \equiv(1-\beta \gamma) u^{\prime}((1-\gamma)[w(k)+b-n k]) \\
& -\rho(R(k)+\delta) u^{\prime}(n(k R(k)-b)-\delta(w(k)+b-n k))=0 .
\end{aligned}
$$

The previous equation defines implicitly a relationship between the steady state value of the capital stock and the amount of bequests, $k=K(b)$. In the next sections we will characterize this relationship as a first step geared towards determining when the bequest motive is operative.

\section{Operative and Inoperative Bequest Motives}

In this section we will provide necessary and sufficient conditions under which parents do not leave bequests to their children. It is immediate to derive from (2.9), (2.17) and (2.18) the following condition:

$$
(1-\beta \gamma)(n+\beta \delta)-\beta\left(f^{\prime}(k)+\delta\right) \geq 0 .
$$


Clearly, if the left hand side of (3.1) is strictly positive, individuals do not leave bequests. Note that, if the bequest motive is not operative, condition (3.1) implies the following:

$$
f^{\prime}(k)<\frac{n}{\beta}-\gamma(n+\beta \delta)<\frac{n}{\beta} .
$$

Therefore, the capital stock in the steady state with inoperative bequest motive is larger than the one associated with the modified golden rule. Thus, in our model positive bequests may appear even if the equilibrium is dynamically inefficient, which is in stark contrast with the result obtained by Weil (1987) for the case with exogenous preferences.

We next extend the analysis of Weil (1987) to the case with preferences exhibiting habit and aspiration formation. For the analysis of the operativeness of the bequest motive, Weil uses the economy with no bequests as a benchmark. That is, he considers the case with $\beta=0$ and, hence, with $b_{t}=0$ for all $t$. However, let us remind that, in contrast with the situation with exogenous preferences, the capital stock of an economy with an inoperative bequest motive depends also on the discount factor if individuals form aspirations. This forces us to modify the procedure for analyzing the operativeness of the bequest motive in our economy. We will thus look at the steady state properties of the economy with altruism $(\beta>0)$ and no bequests $\left(b_{t}=0\right)$ rather than the economy with no altruism $(\beta=0)$. Following Weil (1987), we will restrict our analysis to the case where the steady state equilibrium is saddle-path stable. To this end we introduce the following assumption:

Assumption A. The following conditions hold:

$$
\rho f^{\prime \prime}(k) u^{\prime}\left(\hat{c}^{2}\right)+\rho\left(f^{\prime}(k)+\delta\right) u^{\prime \prime}\left(\hat{c}^{2}\right)\left[n\left(f^{\prime \prime}(k) k+f^{\prime}(k)\right)\right]<0,
$$

and

$$
f^{\prime \prime}(k) k+n \geq 0
$$

The previous assumption ensures that the steady state of the economy with zero bequests is saddle-path stable (see the Appendix). ${ }^{3}$ On the one hand, condition (3.2) is equivalent to the condition appearing in Assumption 2 in De la Croix and Michel (2001) after allowing for habit formation. As pointed by those authors, condition (3.2) is always satisfied with a Cobb-Douglas production function. In particular, given the properties of the production and utility functions, the condition

$$
f^{\prime \prime}(k) k+f^{\prime}(k) \geq 0
$$

is sufficient for (3.2). Is is immediate to see that the sufficient condition (3.4) is always satisfied by a Cobb-Douglas production function. On the other hand, the condition (3.3) coincides with the sufficient condition provided by De la Croix and Michel (2001) for saddle-path stability of the steady state after allowing for population growth. We will maintain Assumption A throughout the rest of the paper.

\footnotetext{
${ }^{3}$ When aspiration formation is absent, the stability conditions of the model with habit formation coincide with those of Galor and Ryder (1989), which guarantee the uniqueness and stability of the steady state of the OLG model with production (Diamond, 1965).
} 
The next lemma establishes that the stationary value of the capital stock is increasing in the stationary amount of bequests:

Lemma 3.1. $K^{\prime}(b)>0$.

Proof. Applying the implicit function theorem to (2.19) we get

$$
K^{\prime}(b)=-\frac{h_{b}}{h_{k}}
$$

where

$$
h_{b}=(1-\gamma)(1-\gamma \beta) u^{\prime \prime}\left(\hat{c}^{1}\right)+\rho(n+\delta)\left(f^{\prime}+\delta\right) u^{\prime \prime}\left(\hat{c}^{2}\right)
$$

and

$$
\begin{aligned}
h_{k}= & -(1-\gamma)(1-\gamma \beta)\left(k f^{\prime \prime}(k)+n\right) u^{\prime \prime}\left(\hat{c}^{1}\right) \\
& -\rho f^{\prime \prime}(k) u^{\prime}\left(\hat{c}^{2}\right)-\rho\left(f^{\prime}(k)+\delta\right) u^{\prime \prime}\left(\hat{c}^{2}\right)\left[n\left(k f^{\prime \prime}(k)+f^{\prime}(k)\right)+\delta\left(k f^{\prime \prime}(k)+n\right)\right]
\end{aligned}
$$

are the partial derivatives of $h(k, b)$ with respect to $b$ and $k$, respectively. From Assumption A and the properties of the utility and production function, we know that $h_{b}<0$ and $h_{k}>0$, which proves the result.

Let $\bar{k}$ be the steady state value of the capital stock per capita when there are no bequests. As we have already said, this stock depends on the altruism factor $\beta$ so that we can write $\bar{k}=\bar{k}(\beta)$. The following lemma characterizes this relationship:

Lemma 3.2. $\bar{k}^{\prime}(\beta)>0$ if $\gamma>0$, whereas $\bar{k}^{\prime}(\beta)=0$ if $\gamma=0$.

Proof. The proof follows directly from the definition of the steady state. The stationary value $\bar{k}$ of the capital stock is implicitly given by equation (2.19) when we impose $b=0$. Implicitly differentiating the previous equation, we get

$$
\frac{d \bar{k}}{d \beta}=\frac{\gamma u^{\prime}\left(\hat{c}^{1}\right)}{h_{k}}
$$

where $h_{k}$ is the partial derivative of $h(k, b)$ with respect to $k$. The numerator of (3.4) is clearly positive while the denominator is also positive as dictated by Assumption A.

The intuition behind the previous lemma is simple. Under aspiration formation, the consumption level of an adult individual affects negatively the utility of their descendants and, hence, thanks to the existence of altruism, this consumption generates disutility to this adult individual. Therefore, a rise in the intensity of altruistic sentiments results in a reduction of the marginal utility of adult consumption relative to that of old consumption. In fact, we see that, for a given value of the individual's consumption vector $\left(c_{t}^{1}, c_{t+1}^{2}\right)$, the marginal utility of adult consumption $c_{t}^{1}$ is equal to $u^{\prime}\left(\hat{c}_{t}^{1}\right)-\beta \gamma u^{\prime}\left(\hat{c}_{t+1}^{1}\right)-\rho \delta u^{\prime}\left(\hat{c}_{t+1}^{2}\right)$, whereas the marginal utility of old consumption $c_{t+1}^{2}$ is $u^{\prime}\left(\hat{c}_{t+1}^{2}\right)$ when there are no bequests. Therefore, an increase in the value of the altruism factor $\beta$ makes adult individuals shift current consumption to the future by means of a large amount of saving. Finally, observe 
that in absence of aspiration formation the altruism factor $\beta$ does not affect the stationary value of the capital stock $\bar{k}$ with zero bequests even if habit formation is present.

From (3.1) we can implicitly define a threshold value of the altruism factor $\beta$, which will be the one solving the following equation:

$$
G(\beta) \equiv(1-\beta \gamma)(n+\beta \delta)-\beta\left[f^{\prime}(\bar{k}(\beta))+\delta\right]=0 .
$$

This threshold value should determine in principle the value of the altruism factor $\beta$ above which the bequest motive is operative, that is, for which altruism is strong enough to enable strictly positive bequests. However, a potential problem with equation (3.6) is that it could have multiple solutions or no solution for $\beta .{ }^{4}$ However, after characterizing the previous equation, we can obtain a precise result about the operativeness of the bequest motive. Let $\bar{\beta}_{i}, i=1,2, \ldots, I$, be the roots of (3.6) with $\bar{\beta}_{i}<\bar{\beta}_{j}$ if $j>i{ }^{5}$ The following result characterizes the operativeness of the bequest motive in terms of the threshold values $\bar{\beta}_{i}$ of the altruism factor:

\section{Proposition 3.3.}

(i) If $\beta \in\left(0, \bar{\beta}_{1}\right)$, then $b=0$.

(ii) If $\beta \in\left(\bar{\beta}_{i}, \bar{\beta}_{i+1}\right)$ where $i$ is an odd integer, then $b>0$.

(iii) If $\beta \in\left(\bar{\beta}_{i}, \bar{\beta}_{i+1}\right)$ where $i$ is an even integer, then $b=0$.

Proof. The result follows from the continuity of $G, G(0)>0$, and (3.1).

In contrast with an economy with exogenous preferences, now the dynamic inefficiency of the economy without altruism is not sufficient to prevent the bequest motive from being operative when individuals are altruistic towards their descendants. Analogously, the dynamic efficiency of the economy with $\beta=0$ is no longer a necessary condition for positive bequests when parents are altruistic towards their children. Since $\bar{k}$ increases with $\beta$, we have that $f^{\prime}(\bar{k}(0))>f^{\prime}(\bar{k}(\beta))$ for all $\beta>0$. Therefore, if the economy without an altruistic motive $(\beta=0)$ is dynamically inefficient $\left(f^{\prime}(\bar{k}(0))<n\right)$, then it holds that $f^{\prime}(\bar{k})<n$. However, as can be seen from (3.6), this is not sufficient for $\bar{\beta}>1$ in an economy with aspiration formation, which means that positive bequests could appear even if the economy with $\beta=0$ is dynamically inefficient.

In the next two sections we will analyze how the strength of habit and aspiration formation affect the operativeness of the bequest motive, that is, for which values of the altruism factor $\beta$ bequests are strictly positive. For simplicity we will focus on two extreme cases. First, we will assume that only habit formation is present $(\delta>0$ and $\gamma=0)$. Second, we will look at the case where individuals form aspirations but no habits $(\delta=0$ and $\gamma>0)$. We also analyze these two cases separately because the two phenomena leading to endogenous preferences have a quite different nature. Habit formation is not an intergenerational but intragenerational phenomenon, while

\footnotetext{
${ }^{4}$ In Section 5 we will show the existence of two solutions for numerical examples where the utility and the production function are logarithmic and Cobb-Douglas, respectively. The largest of these solutions lies above unity, while the smallest can lie either below or slightly above unity.

${ }^{5}$ We disregard the nongeneric roots where $G(\beta)=0$ and $G^{\prime}(\beta)=0$ as any marginal perturbation in the parameter values makes them disappear or convert into a pair of generic solutions.
} 
aspiration formation has a clear intergenerational nature. Therefore, the interaction of these two phenomena with altruism (which has also an intergenerational nature) could give rise to a different dynamic behavior of the economy. In particular, while aspirations have always direct intergenerational effects, regardless of the degree of altruism of individuals, habit formation has only indirect effects through the altruistic links from parents to children.

We will also study how the intensity of habits and aspirations affect the capital stock and the amount of bequests (provided they are positive). This is a qualitative rather than quantitative question since we would like to know if, when the intensity of habits and aspirations changes, individuals react by adjusting only the amount of bequests they leave or they also adjust the amount of saving (i.e., the relative distribution between adult and old consumption).

\section{Habit Formation and the Operativeness of the Bequest Motive}

We are going to assume in this section that individuals form habits but no aspirations $(\delta>0$ and $\gamma=0)$. Therefore, the capital stock $\bar{k}$ of the economy with zero bequests is independent of the altruism factor and, hence, equation (3.6) has a unique solution $\bar{\beta}$ when $\gamma=0$. Obviously, bequests are positive if and only if $\beta>\bar{\beta}$.

To see how the threshold value $\bar{\beta}$ of the altruism factor depends on the habits intensity $\delta$ we must establish first the effect of $\delta$ on the capital stock $\bar{k}$ corresponding to the economy with zero bequests. The next result, already proved by Wendner (2002), shows that, if the steady state is stable, then $\bar{k}$ depends positively on $\delta$.

Lemma 4.1. $\frac{d \bar{k}}{d \delta}>0$.

Proof. This result follows directly from the definition of the steady state capital of the economy with zero bequests. This capital is given implicitly by the equation (2.19) after imposing $b=0$ and $\gamma=0$. Implicitly differentiating that equation we obtain

$$
\frac{d \bar{k}}{d \delta}=\frac{-\rho u^{\prime}\left(\hat{c}^{2}\right)+\rho\left(f^{\prime}+\delta\right) c^{1} u^{\prime \prime}\left(\hat{c}^{2}\right)}{\left(k f^{\prime \prime}(k)+n\right) u^{\prime \prime}\left(\hat{c}^{1}\right)+\rho f^{\prime \prime}(k) u^{\prime}\left(\hat{c}^{2}\right)+\rho\left(f^{\prime}(k)+\delta\right) u^{\prime \prime}\left(\hat{c}^{2}\right)\left[n\left(k f^{\prime \prime}(k)+f^{\prime}(k)\right)+\delta\left(k f^{\prime \prime}(k)+n\right)\right]} .
$$

The numerator of the previous derivative is negative as follows from the properties of $u$, while is immediate to see that the denominator is also negative as a consequence of Assumption A when $\gamma=0$.

The intuition lying behind the previous result is standard in the models of habit formation (Alonso-Carrera et al., 2004b). When habits are present, individuals do not obtain utility only from the total consumption in each period, but also from the comparison of the amount of old consumption with a reference based on their own adult consumption. An increase in the habits intensity reduces the marginal rate of substitution between adult and old consumption, that is, the marginal valuation of adult consumption decreases relative to that of old consumption. Therefore, when $\delta$ increases, individuals raise their amount of saving and this results in a larger stock of capital in equilibrium. 
As occurs for the case without habit formation (Weil, 1987), if the economy where the altruistic links are absent is dynamically inefficiency, then no positive bequests can appear in the economy with altruism. This result is derived directly from imposing $\gamma=0$ in condition (3.1), which means that the critical level of the altruism factor is

$$
\bar{\beta}=\frac{n}{f^{\prime}(\bar{k})} .
$$

Since the capital stock level $\bar{k}$ is independent of $\beta$ when aspirations are absent, this capital stock corresponds to that of the economy with $\beta=0$. Therefore, if $f^{\prime}(\bar{k})<n$, then $\bar{\beta}>1$. Similarly, dynamic efficiency for the economy with $\beta=0$ is necessary, but not sufficient, for positive bequests when altruism is present.

We can now perform the comparative statics exercise relating $\delta$ with the threshold value $\bar{\beta}$ of the altruism factor.

Proposition 4.2. Assume that $\gamma=0$. Then $\frac{d \bar{\beta}}{d \delta}>0$.

Proof. From (4.1), we obtain

$$
\frac{d \bar{\beta}}{d \delta}=-\frac{\bar{\beta} f^{\prime \prime}(\bar{k})\left(\frac{d \bar{k}}{d \delta}\right)}{f^{\prime}(\bar{k})}>0,
$$

where the inequality comes from the properties of the function $f(k)$ and the fact that $\frac{d \bar{k}}{d \delta}>0$ (see Lemma 4.1).

This proposition shows that habits increase the critical value of the altruism factor above which the bequest motive is operative. Therefore, the introduction of habits makes more difficult the existence of positive voluntary bequests. On the one hand, when habits are present, old individuals use their asset holdings to reach the standard of living achieved when they were adults so that their willingness to leave bequests will decrease. That is, since marginal utility is decreasing, equation (2.16) tells us that, as habits intensity increases, the utility loss associated with leaving bequests becomes larger. On the other hand, a larger value of $\delta$ means that the consumption reference increases for the old individuals who has received an inheritance when adult and, therefore, this reduces the utility gain accruing from a larger amount of inheritances. As the two effects we have just discussed go in the same direction, the final outcome is that an increase in the habits intensity results in a lower willingness to leave bequests.

In order to illustrate the previous result, let us compute the critical value $\bar{\beta}$ of the altruism factor for different values of the parameter $\delta$ measuring habits intensity. To this end, we parametrize the economy as in Weil (1987) in order the make the comparison easier. In particular, let us consider a logarithmic utility, $u\left(c_{t}\right)=\ln c_{t}$, and a production function of the Cobb-Douglas type,

$$
f\left(k_{t}\right)=A k_{t}^{\alpha} .
$$

Under logarithmic preferences the propensity to save out of labor income is $h=\rho /(1+\rho)$. In our simulations we consider three alternative values for $h: 0.25$, 
0.5 and 0.75 . We also assume that the share of capital income out of total income is $25 \%$, that is, $\alpha=0.25$. Finally, let us assume that the adulthood period lasts for 35 years so that, if $m$ is the annual gross rate of population growth, then $n=m^{35}$. We will use four alternative values for $m: 1.01,1.03,1.05$ and 1.07 .

Table 1 shows the simulated threshold values $\bar{\beta}$ of the altruism factor for alternative values of the parameter $\delta$. The results suggest that the bequest motive is operative only if the altruism factor takes a very high value, which amounts to a quite low intergenerational discount rate. Moreover, habit formation raises substantially the value of the critical altruism factor. For instance, when $h=0.25$ and $m=1.01$, the threshold value $\bar{\beta}$ of the altruism factor under habit formation when $\delta=0.15$ is a $10.20 \%$ larger than when there is no habit formation $(\delta=0)$. Moreover, the impact of habit formation on the threshold value $\bar{\beta}$ is smaller for larger values of the annual gross rate $m$ of population growth and of the temporal discount factor $\rho$. Note that the introduction of a sufficiently strong level of habit formation allows $\bar{\beta}$ to become larger than unity, which means that the stationary bequests cannot be positive in this case. Moreover, the values larger than unity in Table 1 imply that the corresponding standard OLG economy without altruism is dynamically inefficient.

\section{[Insert Table 1]}

At this point it is obvious that an increase in the intensity $\delta$ of habit formation results in a reduction in the amount of bequests. However, we would like to know if the adjustment brought about by the variation in $\delta$ affects the amount of saving and not only the amount of bequests. We will next provide an answer to this question.

As a first approach to the question we have just posed, note that when the habits intensity $\delta$ increases, individuals would like to reduce their adult consumption. This is so for two reasons. First, by reducing the amount of consumption, habits become less important for the next period. Second, by reducing adult consumption there are more resources available for old consumption, which allows individuals to overcome the negative effect of habits due to the increase in the marginal utility of old consumption triggered by habits. When the bequest motive is inoperative $(\beta<\bar{\beta})$, then the previous effect on saving will occur as shown in Lemma 4.1. However, when the bequest motive is operative $(\beta>\bar{\beta})$, individuals have another strategy at their disposal to accommodate the increase in the habits intensity. This strategy consists on decreasing the amount of bequests left to their descendants in order to increase old consumption without modifying the amount of saving and, thus, leaving unchanged the stock of capital. We are thus left with the question of which of these two possible strategies are followed by individuals when the bequest motive is operative. Note that the cost of reducing the amount of saving and keeping bequests at the same level is the reduction in the utility accruing from own consumption. The cost of reducing the amount of bequests and keeping invariant the amount of saving arises because altruistic individuals internalize the decrease of the initial endowment of their descendants. Depending on the relative magnitudes of these two costs we can give an answer to our previous question.

Proposition 4.3. Assume that $\gamma=0$ and $\beta>\bar{\beta}$. Then, $\frac{d k}{d \delta}=0$ and $\frac{d b}{d \delta}<0$. 
Proof. The steady state value of capital $k$ and bequests $b$ for the economy with habits, positive bequests and no aspirations is given by the following two equations (see (2.19) and (3.1)):

$$
\begin{aligned}
& u^{\prime}\left(f(k)-k f^{\prime}(k)+b-n k\right) \\
& \quad-\rho\left[f^{\prime}(k)+\delta\right] u^{\prime}\left(n\left[k f^{\prime}(k)-b\right]-\delta\left[f(k)+b-k f^{\prime}(k)-n k\right]\right)=0
\end{aligned}
$$

and

$$
n-\beta f^{\prime}(k)=0 .
$$

The second equation tells us that the capital stock $k$ does no depend on the habits intensity $\delta$. Using this fact, we can implicitly differentiate the first equation above to obtain

$$
\frac{d b}{d \delta}=\frac{\rho\left(u^{\prime}\left(\hat{c}^{2}\right)-\left[f^{\prime}(k)+\delta\right] \hat{c}^{1} u^{\prime \prime}\left(\hat{c}^{2}\right)\right)}{u^{\prime \prime}\left(\hat{c}^{1}\right)+\rho(n+\delta)\left[f^{\prime}(k)+\delta\right] u^{\prime \prime}\left(\hat{c}^{2}\right)} .
$$

From the properties of the production and utility functions it is obvious that the previous derivative is negative.

The previous proposition tells us that an increase in the habits intensity results in less bequests but the amount of saving remains unchanged. This means that the induced increase in old consumption is reached thanks to the reduction in the amount of bequests left to the descendants. Obviously, if the habits intensity increases sharply so that $\beta<\bar{\beta}$, then the bequest motive will not be operative any longer. In this case, the decrease in the amount of bequests will not be sufficient to absorb the impact of stronger habits and, therefore, some increase in the amount of saving at the end of the adult period will be also necessary.

\section{Aspirations and the Operativeness of the Bequest Motive}

In this section we will assume that individuals form aspirations only $(\gamma>0$ and $\delta=0$ ). To determine how the likelihood of positive bequests varies with the aspirations intensity $\gamma$, we must establish first the effect of $\gamma$ on the capital stock $\bar{k}$ of the economy with no bequests. De la Croix (1996) finds that $\frac{d \bar{k}}{d \gamma}<0$ in an economy without altruism $(\beta=0)$ when the utility and the production function are logarithmic and Cobb-Douglas, respectively. We will next generalize this result for an economy with altruism $(\beta>0)$ but with zero bequests. Implicitly differentiating condition (2.19) with $\delta=0$ and $b=0$ we get

$$
\frac{d \bar{k}}{d \gamma}=\frac{-\beta\left[u^{\prime}\left(\hat{c}^{1}\right)-\gamma \hat{c}^{1} u^{\prime \prime}\left(\hat{c}^{1}\right)\right]-\hat{c}^{1} u^{\prime \prime}\left(\hat{c}^{1}\right)}{(1-\gamma)(1-\beta \gamma)\left[k f^{\prime \prime}(k)+n\right] u^{\prime \prime}\left(\hat{c}^{1}\right)+\rho f^{\prime \prime}(k) u^{\prime}\left(\hat{c}^{2}\right)+\rho n f^{\prime}(k) u^{\prime \prime}\left(\hat{c}^{2}\right)\left[k f^{\prime \prime}(k)+f^{\prime}(k)\right]} .
$$

The denominator of the previous derivative is negative as follows from Assumption A. However, the sign of the numerator could be ambiguous since aspiration formation affects the individuals' decisions in two ways. On the one hand, when aspirations are present an individual does not obtain utility from his adult consumption but from its comparison with his parent's adult consumption. Thus, an increase in the aspirations intensity forces adult individuals to increase their current consumption 
to outweigh the effect of greater aspirations. In other words, the increase of $\gamma$ raises the marginal value of adult consumption relative to that of old consumption. This first effect is collected by the second term of the numerator of (5.1) and corresponds to the one obtained by De la Croix (1996). ${ }^{6}$ On the other hand, aspiration formation decreases the utility associated with adult consumption of an altruistic individual since the reference of his children is raised accordingly. Therefore, aspirations reduce the relative marginal value of adult consumption. Note that this effect, which is only present when individuals are altruistic, is collected by the first term of the numerator of (5.1). The previous two effects act in opposite directions, but the next result solves the potential ambiguity in the sign of $\frac{d \bar{k}}{d \gamma}$ by means of an appropriate restriction. Let us thus define the index of relative risk aversion $\sigma(c)=-\frac{c u^{\prime \prime}(c)}{u^{\prime}(c)}$. The index $\sigma(c)$ is a measure of the curvature of the utility function and is equal to the inverse of the elasticity of intertemporal substitution.

Lemma 5.1. $\frac{d \bar{k}}{d \gamma}<0$ if and only if $\sigma\left(\hat{c}^{1}\right)>\frac{\beta}{1-\beta \gamma}$.

Proof. The result follows directly from equation (5.1).

The previous result establishes that an increase in the aspirations intensity results in a smaller capital stock provided the elasticity of intertemporal substitution is sufficiently low. A small value of this elasticity means a low willingness to accept an increase in the relative marginal value of adult consumption induced by stronger inherited aspirations. In this case, individuals will raise their adult consumption in order to keep that relative marginal value. Moreover, note that the ratio $\frac{\beta}{1-\beta \gamma}$ is inversely related to the individuals' willingness to accept a reduction in the relative marginal value of adult consumption arising from the interaction between altruism and aspiration formation.

In order to assess the empirical content of the previous lemma, it will be useful to consider the particular case of a marginal introduction of aspirations. The following corollary particularizes immediately the previous lemma to this case:

Corollary 5.2. $\left.\frac{d \bar{k}}{d \gamma}\right|_{\gamma=0}<0$ if and only if $\sigma\left(\hat{c}^{1}\right)>\beta$.

The condition $\sigma(c)>\beta$ seems the more empirically relevant as $\beta<1$ and the vast majority of estimated values of the inverse of the elasticity of intertemporal substitution found in the literature lie above 1 (see Mehra and Prescott, 1985). Under logarithmic preferences we have $\sigma(c)=1$ for all $c$. In this case, and assuming the Cobb-Douglas production function (4.2) as in the simulation of the previous subsection, we obtain that the capital stock per worker $\bar{k}$ is

$$
\bar{k}=\left[\frac{A \rho(1-\alpha)(1-\gamma)}{n(1-\beta \gamma+\rho(1-\gamma))}\right]^{\frac{1}{1-\alpha}} .
$$

It is immediate to see in this case that $\frac{d \bar{k}}{d \gamma}<0$ for all $\gamma$.

\footnotetext{
${ }^{6}$ Note that $\frac{d \bar{k}}{d \gamma}<0$ whenever $\beta=0$.
} 
We can now conduct the comparative statics exercise of changes in the aspirations intensity $\gamma$ on the threshold value $\bar{\beta}$ of the altruism factor. The following proposition provides sufficient conditions for an explicit characterization:

Proposition 5.3. Assume that $\delta=0$ and $\sigma\left(\hat{c}^{1}\right)>\frac{\beta}{1-\beta \gamma}$. Then, an increase in the aspirations intensity $\gamma$ makes larger the range of values of the altruism factor $\beta$ for which the bequest motive is operative.

Proof. Note that

$$
\frac{d G(\beta)}{d \gamma}=-\beta\left[n+f^{\prime \prime}(\bar{k})\left(\frac{d \bar{k}}{d \gamma}\right)\right],
$$

which is negative when $\sigma\left(\hat{c}^{1}\right)>\frac{\beta}{1-\beta \gamma}$, as follows from Lemma 5.1. Hence, the desired result follows directly from Proposition 3.3.

From Proposition 3.3 it is easy to see that the previous results means that, when the elasticity of intertemporal substitution is sufficiently low, aspirations make more likely the existence of positive bequests in equilibrium. The intuition behind this result is clear: under altruism individuals take into account the fact that their adult consumption determines the standard of living of their descendant. Therefore, the increase in the aspirations intensity makes altruistic individuals to raise the fraction of their saving devoted to bequests for a given level of altruism. Note that, as established in Lemma 5.1, since adult consumption increases with the aspirations intensity when $\sigma\left(\hat{c}^{1}\right)>\frac{\beta}{1-\beta \gamma}$, it is obvious that individuals must leave a larger amount of bequests to outweigh the negative effect of aspirations on their descendants felicity. Therefore, as the aspirations intensity rises, the minimal degree of altruism needed for positive bequests goes down.

The following corollary shows that, for a sufficiently low value of the elasticity of intertemporal substitution, the marginal introduction of aspirations reduces the threshold value of the altruism factor above which bequests are strictly positive. Let us recall that when $\gamma=0$ there a exist unique threshold value $\bar{\beta}$ and, by continuity, there exist a unique threshold value for sufficiently small values of the aspirations intensity parameter $\gamma$.

Corollary 5.4. $\left.\frac{d \bar{\beta}}{d \gamma}\right|_{\gamma=0}<0$ if $\sigma\left(\hat{c}^{1}\right)>\beta$.

Proof. This result is obtained directly from applying the implicit function theorem to equation (3.6) and noting that $\left.\frac{d \bar{k}}{d \gamma}\right|_{\gamma=0}<0$ and $\left.\frac{d \bar{k}}{d \beta}\right|_{\gamma=0}=0$.

Using the numerical example of the previous subsection, let us compute the threshold values $\bar{\beta}_{i}$ of the altruism factor for different values $\gamma$ of the aspirations intensity parameter. In this numerical example there are two threshold values $\bar{\beta}_{1}$ and $\bar{\beta}_{2}$, with $\bar{\beta}_{1}<\bar{\beta}_{2}$. Moreover, in all the simulations we have conducted $\bar{\beta}_{2}$ is larger than unity, whereas $\bar{\beta}_{1}$ could be larger or smaller than 1 . Table 2 shows the simulated values for the altruism factor $\bar{\beta}_{1}$. The results suggest that aspiration 
formation reduces significatively that threshold value. For instance, when $h=0.25$ and $m=1.01$, the value of $\bar{\beta}_{1}$ for an economy with aspiration formation with $\gamma=0.2$ is a $14.29 \%$ smaller than in an economy without aspiration formation. Moreover, the impact of the aspirations intensity in the threshold value of the altruism factor $\bar{\beta}_{1}$ is larger for larger values of the annual gross rate $m$ of population growth and of the temporal discount factor $\rho$. Note that in some cases aspiration formation makes the value $\bar{\beta}_{1}$ to become smaller than 1 while that value was larger than 1 with no aspirations.

\section{[Insert Table 2]}

Let us recall that, in contrast with the economy without aspiration formation, the dynamic inefficiency of the economy with no altruism is no longer sufficient to prevent bequests from being positive in an economy with altruistic agents. Similarly, the dynamic efficiency of the economy without altruism is no longer a necessary condition for the operativeness of the bequest motive in the economy with altruism when $\delta=0$. The threshold value of the altruism factor given in (3.6) can be written as

$$
\bar{\beta}=\frac{n}{f^{\prime}(\bar{k})+\gamma n} .
$$

Since $\bar{k}$ is increasing in $\beta$, we have that $f^{\prime}(\bar{k}(0))>f^{\prime}(\bar{k}(\beta))$ for all $\beta>0$. Therefore, if the economy without altruism $(\beta=0)$ is dynamically inefficient $\left(f^{\prime}(\bar{k}(0))<n\right)$, then it holds that $f^{\prime}(\bar{k})<n$. However this is not sufficient for having $\bar{\beta}>1$ in an economy with aspirations since there is an additional positive term in the denominator of expression (5.2), which allows for the existence of positive bequests even if the economy without altruism is dynamically inefficient. In fact, it is possible to have an operative bequest motive even if the economy with altruism but no positive bequests is dynamically inefficient. Therefore, we should notice that a value smaller than 1 in Table 2 does not mean that the economy associated with an altruism factor $\beta$ smaller than $\bar{\beta}_{1}$ is dynamically efficient.

We have already pointed out that an increase in the aspirations intensity $\gamma$ results in larger bequests for the empirically relevant case $\left(\sigma\left(\hat{c}^{1}\right)>\frac{\beta}{1-\beta \gamma}\right)$. However, we have to determine whether individuals adjust only the amount of bequests they leave or they also adjust the amount of saving. We next turn to this question.

As we have already seen, an increase in the aspirations intensity has two opposite effects on the individual's welfare. On the one hand, it raises the marginal utility of adult consumption. On the other hand, it raises the marginal utility associated with their descendants' welfare. Therefore, the final effect will depend on which of the previous two opposite effects dominates. When there are no bequests, we showed that the final effect depended on the index of relative aversion evaluated at the level of adult consumption. However, the effects of a change in the aspirations intensity could be quite different if the bequest motive is operative. In this case, individuals not only can use the capital stock to accommodate the aspirations shock but they can also use the amount of bequests left to their descendants. The following result characterizes the effects of aspirations intensity on the capital stock and on bequests: 
Proposition 5.5. Assume that $\delta=0$ and $b>0$. Then, $\frac{d k}{d \gamma}>0$, whereas $\frac{d b}{d \gamma}>0$ if $\sigma\left(\hat{c}^{1}\right)>\frac{\beta}{1-\beta \gamma}$.

Proof. The steady state value of capital $k$ and bequests $b$ for the economy with aspirations, positive bequests and no habits is given by the following two equations (see (2.19) and (3.1)):

$$
(1-\beta \gamma) u^{\prime}\left([1-\gamma]\left[f(k)-k f^{\prime}(k)+b-n k\right]\right)-\rho\left(f^{\prime}(k)\right) u^{\prime}\left(n\left(k f^{\prime}(k)-b\right)\right)=0,
$$

and

$$
n(1-\beta \gamma)-\beta f^{\prime}(k)=0 .
$$

Implicitly differentiating the second equation we get the following derivative:

$$
\frac{d k}{d \gamma}=-\frac{n}{f^{\prime \prime}(k)}
$$

which is clearly positive. Using the previous derivative, we can implicitly differentiate the first equation to obtain

$$
\frac{d b}{d \gamma}=-\frac{\Theta}{(1-\gamma)(1-\beta \gamma) u^{\prime \prime}\left(\hat{c}^{1}\right)+\rho f^{\prime}(k) u^{\prime \prime}\left(\hat{c}^{2}\right)},
$$

where the denominator is clearly negative and the numerator is

$$
\begin{aligned}
\Theta= & -(1-\beta \gamma) u^{\prime}\left(\hat{c}^{1}\right)\left[\frac{\beta}{1-\beta \gamma}-\sigma\left(\hat{c}^{1}\right)\right] \\
& -\left[(1-\gamma)(1-\beta \gamma)\left(k f^{\prime \prime}+n\right) u^{\prime \prime}\left(\hat{c}^{1}\right)+\rho f^{\prime \prime} u^{\prime}\left(c_{2}\right)+\rho n f^{\prime} u^{\prime \prime}\left(c_{2}\right)\left(k f^{\prime \prime}+f^{\prime}\right)\right] \frac{d k}{d \gamma} .
\end{aligned}
$$

The second term in $\Theta$ is positive because of both the stability conditions imposed by Assumption A and the sign of $\frac{d k}{d \gamma}$. Moreover, the first term in $\Theta$ is positive if and only if $\sigma\left(\hat{c}^{1}\right)>\frac{\beta}{1-\beta \gamma}$.

The previous result tells us that when bequests are positive individuals accommodate the increase in the aspirations intensity by increasing their saving levels. This allows altruistic individuals to keep the aspirations of their descendants to a moderate level. Moreover, under the condition $\sigma\left(\hat{c}^{1}\right)>\frac{\beta}{1-\beta \gamma}$, individuals leave larger bequests to their descendants in order to outweigh the effect of stronger aspirations.

\section{Effects of Public Debt under Endogenous Preferences}

In this section we analyze how the method used to finance an exogenous level of government spending affects capital accumulation. We compare the issue of public debt against lump sum taxation when both habits and aspirations are present but the bequest motive is not operative. Needless to say, according to the Ricardian proposition, marginal changes in the financing method are irrelevant when bequests 
are positive (see Barro, 1974). We will assume that the government can tax adult and old individuals and that the government spending per worker is constant. Therefore, the government budget is

$$
g=\tau^{1}+\frac{\tau^{2}}{n}+n p_{t+1}-R_{t} p_{t}
$$

where $p_{t}$ is the stock of outstanding public debt per worker in period $t$, while $\tau^{1}$ and $\tau^{2}$ are the constant lump sum taxes paid by adult and old individuals, respectively. The previous constraint at the steady state becomes

$$
g=\tau^{1}+\frac{\tau^{2}}{n}-\left(f^{\prime}(k)-n\right) p
$$

On the other hand, the capital market equilibrium condition (2.11) becomes

$$
s_{t}=n\left(k_{t+1}+p_{t+1}\right)
$$

since now saving is used to make loans to the firms and to the government by means of the acquisition of public debt. The first order condition (2.17) of the consumer's problem at the steady state becomes

$$
\begin{aligned}
& \varphi(k, p) \equiv(1-\beta \gamma) u^{\prime}\left((1-\gamma)\left(w(k)-\tau_{1}-n(k+p)\right)\right) \\
& -\rho(R(k)+\delta) u^{\prime}\left(n R(k)(k+p)-\tau_{2}-\delta\left(w(k)-\tau_{1}-n(k+p)\right)\right)=0 .
\end{aligned}
$$

This condition defines implicitly the capital stock as a function of the stationary stock of public debt. This relation will allow us to characterize the crowding-out effect on private saving of public debt.

Let us analyze the effect of the introduction of public debt when only one of the two taxes is modified so as to satisfy the budget constraint of the government. We consider first the case where only the taxes paid by adult individuals (workers) varies. Therefore, we differentiate (6.2) at the point $p=0$ with $d \tau^{2}=0$, so that $d \tau^{1}=\left[f^{\prime}(k)-n\right] d p$. We can thus implicitly differentiate (6.4) to obtain

$$
\left.\frac{\partial k}{\partial p}\right|_{p=0, d \tau^{2}=0}=\frac{(1-\gamma)(1-\gamma \beta) f^{\prime}(k) u^{\prime \prime}\left(\hat{c}^{1}\right)+\rho(n+\delta) f^{\prime}(k)\left(f^{\prime}(k)+\delta\right) u^{\prime \prime}\left(\hat{c}^{2}\right)}{\varphi_{k}}
$$

where

$$
\begin{aligned}
\varphi_{k}= & -(1-\gamma)(1-\gamma \beta)\left(k f^{\prime \prime}(k)+n\right) u^{\prime \prime}\left(\hat{c}^{1}\right)-\rho f^{\prime \prime}(k) u^{\prime}\left(\hat{c}^{2}\right) \\
& -\rho\left(f^{\prime}(k)+\delta\right) u^{\prime \prime}\left(\hat{c}^{2}\right)\left[n\left(k f^{\prime \prime}(k)+f^{\prime}(k)\right)+\delta\left(k f^{\prime \prime}(k)+n\right)\right]
\end{aligned}
$$

is the derivative of $\varphi(k, p)$ with respect to $k$. The derivative $\frac{\partial k}{\partial p}$ is negative since its denominator is positive as dictated by Assumption A and the numerator is clearly negative by the properties of the production and the utility functions.

Similarly, if the marginal introduction of public debt is accompanied exclusively by a modification of the taxes paid by old individuals $\left(d \tau^{1}=0\right)$, we have that $d \tau^{2}=n[R(k)-n] d p$ and we will thus get

$$
\left.\frac{\partial k}{\partial p}\right|_{p=0, d \tau^{1}=0}=\frac{n(1-\gamma \beta) u^{\prime \prime}\left(\hat{c}^{1}\right)+\rho n(n+\delta)\left(f^{\prime}(k)+\delta\right) u^{\prime \prime}\left(\hat{c}^{2}\right)}{\varphi_{k}}<0,
$$


since the denominator is positive by Assumption A and the numerator is again negative by the properties of the production and the utility functions.

The conclusion of the previous analysis is that the marginal introduction of public deficits, together with only a modification of the taxes paid by individuals belonging to the same age group, reduces the capital intensity and, hence, increases the real interest rate. Therefore, the crowding-out effect of public debt presented by Diamond (1965) is preserved under habit and aspiration formation. Therefore, Ricardian equivalence also fails in this context when the bequest motive is inoperative.

\section{Conclusion and Extensions}

We have analyzed an OLG model where the members of a family are connected by altruistic links and individuals form habits and aspirations. Therefore, the standard of living parametrized by past consumption experiences matters in order to evaluate the utility from current consumption. We have seen that aspirations (based on he standard of living of parents) make easier the existence of positive bequests, whereas habits (based on the own past consumption) make more difficult the operativeness of the bequest motive. Since the joint introduction of aspirations and habits appears as natural in our model, we must conclude that the final effect of the presence of endogenous preferences on the operativeness of the bequest motive is ambiguous. Obviously, the lack of positive bequests allows public deficits to have a real impact in the economy.

In our model there exists a consumption externality brought about by aspirations formation since adult consumption determines the consumption reference of the next generation. However, when altruism is present and the bequest motive is operative, adult individuals do internalize the effect on their descendants' welfare and, therefore, the decentralized solution is already efficient. In this case, the tax policy lacks of any role in the maximization of social welfare.

If the altruism factor lies on the interval where bequests are absent $(\beta<\bar{\beta})$, then a clear inefficiency appears since individuals do not internalize the effect of aspirations. In particular, there exists an excess of adult consumption and, thus, a suboptimally low level of saving. An optimal tax policy should consist on a subsidy to physical capital investment or a tax on adult consumption. De la Croix and Michel (1999) have already analyzed the optimal subsidy to investment geared towards the internalization of aspirations. This fiscal policy induces the adjustment in adult consumption and the achievement of a saving rate consistent with the modified golden rule.

A task left for future research is the analysis of the size of the crowding-out effect when the bequest motive is inoperative. This size will obviously depend on the habits and aspirations intensity. However, this task is unfeasible in our general model and, thus, the analysis should be conducted under specific functional forms and parametric restrictions. 


\section{References}

[1] Abel A. (1986), Capital Accumulation and Uncertain Lifetimes with Adverse Selection, Econometrica 54, 1079-1097.

[2] Abel, A. (1987), Operative Gift and Bequest Motives, American Economic Review 77, 1037-1047.

[3] Abel, A. (1990), Asset Prices under Habit Formation and Catching up with the Joneses, American Economic Review 80, 38-42.

[4] Abel, A. (1999), Risk Premia and Term Premia in General Equilibrium, Journal of Monetary Economics 43, 3-33.

[5] Abel, A. (2003), Optimal Taxation when Consumers Have Endogenous Benchmark Levels of Consumption, forthcoming in Review of Economic Studies.

[6] Alonso-Carrera, J., Caballé, J., and Raurich X. (2004a), Growth, Habit Formation, and Catching Up with the Joneses, forthcoming in European Economic Review.

[7] Alonso-Carrera, J., Caballé, J., and Raurich X. (2004b), Consumption Externalites, Habit Formation and Equilibrium Efficiency, forthcoming in Scandinavian Journal of Economics.

[8] Barro, R.J. (1974), Are Government Bonds Net Wealth? Journal of Political Economy 82, 1095-1117.

[9] Caballé, J. (1995), Endogenous Growth, Human Capital, and Bequest in a LifeCycle Model, Oxford Economic Papers 47, 156-181.

[10] Caballé, J. (1998), Growth Effects of Fiscal Policy under Altruism and Low Elasticity of Intertemporal Substitution, Economic Journal 108, 91-104.

[11] Carroll, C., Overland, J., and Weil, D. (1997), Comparison Utility in a Growth Model, Journal of Economic Growth 2, 339-367.

[12] Carroll, C., Overland, J., and Weil, D. (2000), Saving and Growth with Habit Formation, American Economic Review 90, 341-355.

[13] Cass, D. (1972), On Capital Overaccumulation in the Aggregate, Neoclassical Model of Economic Growth: A Complete Characterization, Journal of Economic Theory 4, 200-223.

[14] De la Croix, D. (1996), The Dynamics of Bequeathed Tastes, Economics Letters $51,89-96$.

[15] De la Croix, D. and Michel P. (1999), Optimal Growth when Tastes Are Inherited, Journal of Economic Dynamics and Control 23, 519-537.

[16] De la Croix, D. and Michel P. (2001), Altruism and Self-Restraint, Annales d'Economie et de Statistique 63-64, 233-260. 
[17] Diamond, P.A. (1965), National Debt in a Neoclassical Growth Model, American Economic Review 55, 1126-1150.

[18] Dynan, K.E., Skinner, J. and Zeldes, S.P. (2002), The Importance of Bequest and Life-Cycle Saving in Capital Accumulation: A New Answer, American Economic Review (Papers and Proceedings) 92, 274-278.

[19] Galor, O. and Ryder, H. (1989), Existence, Uniqueness and Stability of Equilibrium in Overlapping Generations Model with Productive Capital, Journal of Economic Theory 49, 360-375.

[20] Jellal, M. and Wolff, F.C. (2002), Altruistic Bequests with Inherited Tastes, International Journal of Business and Economics 1, 95-113.

[21] Lahiri, A. and Puhakka, P. (1998), Habit Persistence in Overlapping Generations Economies under Pure Exchange, Journal of Economic Theory 78, 176- 188.

[22] Laitner, J.P. (1988), Bequests, Gifts and Social Security, Review of Economic Studies 55, 275-299.

[23] Lettau, M. and Uhlig, H. (2000), Can Habit Formation Be Reconciled with Business Cycles Facts? Review of Economic Dynamics 3, 79-99.

[24] Ljungqvist, L. and Uhlig, H. (2000), Tax Policy and Aggregate Demand Management under Catching Up with the Joneses, American Economic Review 90, 356-366.

[25] Shieh, J., Lai, C., and Chang, W. (2000), Addictive Behaviour and Endogenous Growth, Journal of Economics 72, 263-273.

[26] Weil, P. (1987), Love thy Children: Reflections on the Barro Debt Neutrality Theorem, Journal of Monetary Economics 19, 377-391.

[27] Wendner, R. (2002), Capital Accumulation and Habit Formation, Economics Bulletin 4, 1-10. 


\section{A. Appendix}

In this appendix we analyze the stability properties of the general model when the bequest motive is inoperative, that is, when $b_{t}=0$ for all $t$. In order to obtain a saddle-path stable steady state, we need to have only two eigenvalues with modulus smaller than 1 since the model has two state variables. We thus extend the analysis of De la Croix and Michel (2001) to the case where individuals form habits in addition to aspirations.

The equilibrium dynamics can be written as the following third order difference equation, which is obtained immediately from (2.15), the individuals' budget constraint, and the competitive rental prices:

$$
-u^{\prime}\left(c_{t}^{1}-\gamma c_{t-1}^{1}\right)+\rho\left[R\left(k_{t+1}\right)+\delta\right] u^{\prime}\left(n R\left(k_{t+1}\right) k_{t+1}-\delta c_{t}^{1}\right)+\beta \gamma u^{\prime}\left(c_{t+1}^{1}-\gamma c_{t}^{1}\right)=0,
$$

where

$$
c_{t+i}^{1}=w\left(k_{t+i}\right)-n k_{t+i+1}, \quad \text { for } i=-1,0,1 .
$$

Consider a steady state $\left\{\bar{c}^{1}, \bar{k}\right\}$ satisfying $(1-\beta \gamma)(n+\beta \delta)-\beta\left(f^{\prime}(k)+\delta\right)>0$, which means that in this steady state individuals do not leave bequests to their descendants (see (3.1)). Linearizing around this steady state we get

$$
\begin{aligned}
-\left[\left(1+\beta \gamma^{2}\right) u^{\prime \prime}\right. & \left.\left(\hat{c}^{1}\right)-g_{\bar{c}^{1}}\left(\bar{k}, \bar{c}^{1}\right)\right] d c_{t}^{1} \\
& +\gamma u^{\prime \prime}\left(\hat{c}^{1}\right) d c_{t-1}^{1}+\beta \gamma u^{\prime \prime}\left(\hat{c}^{1}\right) d c_{t+1}^{1}+g_{\bar{k}}\left(\bar{k}, \bar{c}^{1}\right) d k_{t+1}=0,
\end{aligned}
$$

where

$$
\begin{gathered}
d c_{t+i}^{1}=w^{\prime}\left(k_{t+i}\right) d k_{t+i}-n d k_{t+i+1} \quad i=-1,0,1, \\
g\left(\bar{k}, \bar{c}^{1}\right)=\rho[R(\bar{k})+\delta] u^{\prime}\left(n R(\bar{k}) \bar{k}-\delta \bar{c}^{1}\right), \\
g_{\bar{c}^{1}}\left(\bar{k}, \bar{c}^{1}\right)=-\rho \delta(R(\bar{k})+\delta) u^{\prime \prime}\left(\hat{c}^{2}\right)>0, \\
g_{k}\left(\bar{k}, \bar{c}^{1}\right)=\rho R^{\prime}(\bar{k}) u^{\prime}\left(\hat{c}^{2}\right)+\rho n[R(\bar{k})+\delta] u^{\prime \prime}\left(\hat{c}^{2}\right)\left[R(\bar{k})+R^{\prime}(\bar{k}) \bar{k}\right], \\
\hat{c}^{1}=\bar{c}^{1}-\gamma \bar{c}^{1},
\end{gathered}
$$

and

$$
\hat{c}^{2}=n R(\bar{k}) \bar{k}-\delta \bar{c}^{1} .
$$

Note that condition (3.2) in Assumption A is equivalent to assume that

$$
g_{k}\left(\bar{k}, \bar{c}^{1}\right)<0 .
$$

Substituting $d c_{t+i}^{1}$ by $w^{\prime}\left(k_{t+i}\right) d k_{t+i}-n d k_{t+i+1}$ in (A.1), we obtain the characteristic polynomial

$-\left[\left(1+\beta \gamma^{2}\right) u^{\prime \prime}\left(\hat{c}^{1}\right)-g_{\bar{c}^{1}}\left(\bar{k}, \bar{c}^{1}\right)\right]\left(w^{\prime} \lambda-n \lambda^{2}\right)+\gamma u^{\prime \prime}\left(\hat{c}^{1}\right)\left(1+\beta \lambda^{2}\right)\left(w^{\prime}-n \lambda\right)+g_{k} \lambda^{2}=0$,

where we have substituted $d k_{t+i}$ by $\lambda^{i+1}$, with $i=-1,0,1,2$, and used the notation $w^{\prime}=w^{\prime}(\bar{k}), R=R(\bar{k})$ and $g_{k}=g_{k}\left(\bar{k}, \bar{c}^{1}\right)$. Dividing the previous polynomial by $-\gamma u^{\prime \prime}\left(\hat{c}^{1}\right)$ we get the following:

$$
P(\lambda)=\left(n \lambda-w^{\prime}\right) Q(\lambda)-\psi \lambda^{2},
$$


with

$$
\begin{gathered}
Q(\lambda)=\beta \lambda^{2}-\phi \lambda+1, \\
\psi=\frac{g_{k}}{\gamma u^{\prime \prime}\left(\hat{c}^{1}\right)}>0,
\end{gathered}
$$

and

$$
\phi=\frac{\left[+\left(1+\beta \gamma^{2}\right) u^{\prime \prime}\left(\hat{c}^{1}\right)-g_{\bar{c}^{1}}\left(\bar{k}, \bar{c}^{1}\right)\right]}{\gamma u^{\prime \prime}\left(\hat{c}^{1}\right)}>0 .
$$

Lemma A.1. The polynomial $Q(\lambda)$ has two positive real roots, $\mu_{1}$ and $\mu_{2}$, satisfying $0<\mu_{1} \leq 1<1 / \beta \leq \mu_{2}$.

Proof. For $\lambda=1$ we have

$$
Q(1)=1+\beta-\phi=-\frac{\left[(1-\gamma)(1-\beta \gamma) u^{\prime \prime}\left(\hat{c}^{1}\right)-g_{\bar{c}^{1}}\left(\bar{k}, \bar{c}^{1}\right)\right]}{\gamma u^{\prime \prime}\left(\hat{c}^{1}\right)} \leq 0 .
$$

Since $Q(0)=1>0$, then $Q(\lambda)$ is equal to zero at a point $\mu_{1}$ of the interval $(0,1]$. The characteristic polynomial $Q(\lambda)$ can be written as

$$
Q(\lambda)=\beta\left(\lambda^{2}-\frac{\phi}{\beta} \lambda+\frac{1}{\beta}\right),
$$

and we know that

$$
Q(\lambda)=\beta\left[\lambda^{2}-\left(\mu_{1}+\mu_{2}\right) \lambda+\left(\mu_{1} \mu_{2}\right)\right] .
$$

Therefore the product of the two roots is equal to $1 / \beta$ so that $\mu_{2}=1 /\left(\beta \mu_{1}\right) \geq 1 / \beta$.

Lemma A.2. The largest eigenvalue $\lambda_{1}$ satisfies $\lambda_{1}>1 / \beta$ and $\lambda_{1}>w^{\prime} / n$.

Proof. Note that $\lim _{\lambda \rightarrow \infty} P(\lambda)=\infty$. Moreover, $P\left(\mu_{2}\right)=-\psi\left(\mu_{2}\right)^{2}<0$ as $Q\left(\mu_{2}\right)=0$ by definition. Therefore, $\lambda_{1}>\mu_{2} \geq 1 / \beta$. Similarly, $P\left(\frac{w^{\prime}}{n}\right)=-\psi\left(\frac{w^{\prime}}{n}\right)^{2}<0$. We thus conclude that $\lambda_{1}>w^{\prime} / n$.

The previous result rules out the possibility of having three eigenvalues with modulus lying on the interval $(-1,1)$, which means that it is not possible to have a locally indeterminate stationary equilibrium.

The other two eigenvalues $\lambda_{2}$ and $\lambda_{3}$ are real or conjugate complex. The polynomial $P(\lambda)$ can be written as

$$
P(\lambda)=-n \beta\left[-\lambda^{3}+\left(\frac{\beta w^{\prime}+n \phi+\psi}{n \beta}\right) \lambda^{2}-\left(\frac{n+\phi w^{\prime}}{n \beta}\right) \lambda+\frac{w^{\prime}}{n \beta}\right] .
$$

Therefore,

$$
\lambda_{1} \lambda_{2} \lambda_{3}=\frac{w^{\prime}}{n \beta}
$$

and

$$
\lambda_{1}+\lambda_{2}+\lambda_{3}=\frac{\beta w^{\prime}+n \phi+\psi}{n \beta},
$$

so that $\lambda_{2}$ and $\lambda_{3}$ are the roots of the polynomial

$$
\lambda^{2}-\left(\frac{\beta w^{\prime}+n \phi+\psi}{n \beta}-\lambda_{1}\right) \lambda+\frac{w^{\prime}}{n \beta \lambda_{1}}=0 .
$$


Lemma A.3. The steady state equilibrium is saddle-path stable if and only if $P(1)<0$ and $\lambda_{1}>w^{\prime} / n \beta$.

Proof. (Necessity) On the one hand, if $P(1) \geq 0$, and since $P\left(\mu_{2}\right)<0$ and $\lim _{\lambda \rightarrow \infty} P(\lambda)=\infty$, then there exists a second real eigenvalue $\lambda_{2}$ satisfying $\lambda_{2} \geq 1$ and, therefore, the steady state is unstable. Therefore, stability imposes the condition $P(1)<0$. On the other hand, stability implies that $1>\lambda_{2} \lambda_{3}=w^{\prime} / n \beta \lambda_{1}$ and, hence, the condition $\lambda_{1}>w^{\prime} / n \beta$ is also necessary.

(Sufficiency) (a) When $\lambda_{2}$ and $\lambda_{3}$ are real, they are positive since $P(\lambda)<0$ when $\lambda \leq 0$. Moreover, in that case, $P(1)<0$ implies that both $\lambda_{2}$ and $\lambda_{3}$ are either larger or smaller than 1 . Note that, if only one of the eigenvalues is smaller than 1 , then $P(1)>0$ as $\lim _{\lambda \rightarrow \infty} P(\lambda)=\infty$. Since $\lambda_{2} \lambda_{3}=w^{\prime} / n \beta \lambda_{1}<1$, both eigenvalues are smaller than 1 .

(b) When $\lambda_{2}$ and $\lambda_{3}$ are complex, we have $\left|\lambda_{2}\right|^{2}=\left|\lambda_{3}\right|^{2}=\lambda_{2} \lambda_{3}=w^{\prime} / n \beta \lambda_{1}<1$.

Proposition A.4. If Assumption A holds, then the steady state equilibrium is saddle-path stable.

Proof. Consider the conditions stated in Lemma A.3. Condition $P(1)<0$ can be written as

$$
\left(n-w^{\prime}\right)(\beta-\phi+1)-\psi<0 .
$$

Note that $Q(1)=1+\beta-\phi$ is non-positive and $\psi$ is positive by condition (3.2) and the properties of the utility function. Therefore, thanks to condition (3.3) in Assumption A, which is equivalent to $w^{\prime} \leq n$, the inequality (A.4) holds. Moreover, (3.3) and $n \geq 1$ imply that

$$
\frac{w^{\prime}}{n \beta \lambda_{1}} \leq \frac{1}{\beta \lambda_{1}}<1
$$

where the second inequality holds because of Lemma A.2. We have thus proved that Assumption A is sufficient for saddle-path stability. 
Table 1. The critical value $\bar{\beta}$ as a function of $\delta, h$ and $m$.

\begin{tabular}{|c|c|c|c|c|c|}
\hline & \multirow[b]{2}{*}{$\delta$} & \multicolumn{4}{|c|}{$m$} \\
\hline & & 1.01 & 1.03 & 1.05 & 1.07 \\
\hline \multicolumn{6}{|l|}{$h=0.25$} \\
\hline & 0 & 0.49 & 0.59 & 0.66 & 0.70 \\
\hline & 0.05 & 0.51 & 0.61 & 0.67 & 0,71 \\
\hline & 0.15 & 0.54 & 0.64 & 0.69 & 0.72 \\
\hline & 0.25 & 0.57 & 0.67 & 0.71 & 0,73 \\
\hline & 0.5 & 0.64 & 0.74 & 0.77 & 0.77 \\
\hline & 0.75 & 0.69 & 0.82 & 0.83 & 0.80 \\
\hline \multicolumn{6}{|l|}{$h=0.5$} \\
\hline & 0 & 0.73 & 0.98 & 1.18 & 1.32 \\
\hline & 0.05 & 0.74 & 0.99 & 1.19 & 1.32 \\
\hline & 0.15 & 0.75 & 1.01 & 1.21 & 1.34 \\
\hline & 0.25 & 0.77 & 1.03 & 1.23 & 1.35 \\
\hline & 0.5 & 0.80 & 1.07 & 1.27 & 1.38 \\
\hline & 0.75 & 0.82 & 1.11 & 1.32 & 1.42 \\
\hline \multicolumn{6}{|l|}{$h=0.75$} \\
\hline & 0 & 0.87 & 1.25 & 1.60 & 1.86 \\
\hline & 0.05 & 0.87 & 1.26 & 1.60 & 1.86 \\
\hline & 0.15 & 0.88 & 1.26 & 1.61 & 1.87 \\
\hline & 0.25 & 0.88 & 1.27 & 1.62 & 1.88 \\
\hline & 0.5 & 0.89 & 1.29 & 1.65 & 1.90 \\
\hline & 0.75 & 0.90 & 1.31 & 1.67 & 1.92 \\
\hline
\end{tabular}


Table 2. The critical value $\bar{\beta}$ as a function of $\gamma, h$ and $m$.

\begin{tabular}{llllll}
\hline \hline & & \multicolumn{5}{c}{$m$} \\
\cline { 2 - 5 } & $\gamma$ & 1.01 & 1.03 & 1.05 & 1.07 \\
\hline$h=0.25$ & & & & & \\
& 0 & 0.49 & 0.59 & 0.66 & 0.70 \\
& 0.05 & 0.47 & 0.58 & 0.63 & 0.67 \\
& 0.1 & 0.45 & 0.54 & 0.60 & 0.64 \\
& 0.15 & 0.44 & 0.52 & 0.57 & 0.61 \\
& 0.2 & 0.42 & 0.50 & 0.55 & 0.58 \\
& & & & & \\
$h=0.5$ & & & & & \\
& 0 & 0.73 & 0.98 & 1.18 & 1.32 \\
& 0.05 & 0.70 & 0.93 & 1.12 & 1.24 \\
& 0.1 & 0.67 & 0.89 & 1.06 & 1.17 \\
& 0.15 & 0.65 & 0.85 & 1.00 & 1.11 \\
& 0.2 & 0.62 & 0.81 & 0.95 & 1.05 \\
& & & & & \\
& & & & & \\
& 0 & 0.87 & 1.25 & 1.60 & 1.86 \\
& 0.05 & 0.83 & 1.19 & 1.49 & 1.71 \\
& 0.1 & 0.80 & 1.11 & 1.39 & 1.60 \\
& 0.15 & 0.77 & 1.05 & 1.30 & 1.47 \\
& 0.2 & 0.74 & 1.00 & 1.22 & 1.37 \\
& & & & & \\
\hline
\end{tabular}

